\title{
Mosaic trisomy 17 in amniocytes: phenotypic outcome, tissue distribution, and uniparental disomy studies
}

\author{
Maurizio Genuardi ${ }^{1}$, Carla Tozzi ${ }^{2}$, Maria Grazia Pomponi ${ }^{1}$, Maria Letizia Stagni ${ }^{2}$, \\ Matteo Della Monica ${ }^{3}$, Gioacchino Scarano ${ }^{3}$, Fabrizio Calvieri ${ }^{2}$, Loredana Torrisi ${ }^{1}$ and \\ Giovanni Neri ${ }^{1}$
}

${ }^{1}$ Istituto di Genetica Medica, Facoltà di Medicina e Chirurgia 'A Gemelli', Università Cattolica del S Cuore

${ }^{2}$ Laboratorio di Citogenetica, Servizio di Istologia ed Anatomia Patologica, Complesso Ospedaliero

S Giovanni-Addolorata, Rome

${ }^{3}$ Servizio di Genetica Medica, Ospedale S Giuseppe Moscati, Avellino, Italy

\begin{abstract}
Mosaicism for trisomy 17 in amniocyte cultures is a rare finding, whilst postnatal cases are exceptional. In order to gain insight into the possible effects of the distribution of the trisomic line and of uniparental disomy (UPD) on embryofoetal development, we have performed follow-up clinical, cytogenetic and molecular investigations into three newly detected prenatal cases of trisomy 17 mosaicism identified in cultured amniotic fluid. In the first case, the pregnancy ended normally with the birth of a healthy girl, and analysis of newborn lymphocytes and of multiple extra-embryonic tissues was indicative of confined placental mosaicism. The second case was also associated with a normal pregnancy outcome and postnatal development, and only euploid cells were found in peripheral blood after birth. However, maternal isodisomy 17 consequent to a meiosis II error and loss of a chromosome 17 homologue was detected in peripheral lymphocytes postnatally. In the third case, pathological examination after termination of pregnancy showed growth retardation and minor dysmorphisms, and the trisomic line was detected in foetal skin fibroblasts. In addition, biparental derivation of chromosome 17 was demonstrated in the euploid lineage. These results, together with previously reported data, indicate that true amniotic trisomy 17 mosaicism is more commonly of extra-embryonic origin and associated with normal foetal development. Phenotypic consequences may arise when the trisomic line is present in foetal tissues. Case 2 also represents the first observation of maternal UPD involving chromosome 17; the absence of phenotypic anomalies in the child suggests that chromosome 17 is not likely to be subject to imprinting in maternal gametes.
\end{abstract}

Keywords: aneuploidy; chromosome 17; mosaicism; prenatal diagnosis; uniparental disomy

Correspondence: Maurizio Genuardi MD, Istituto di Genetica Medica, Università Cattolica del S Cuore, Largo Francesco Vito 1, 00168 Rome, Italy. Tel: + 390630154927 ; Fax: +39063050031; E-mail: mgenuardi@rm.unicatt.it

Received 9 October 1998; revised 20 January 1999; accepted 25 January 1999 


\section{Introduction}

Mosaicism for a chromosome anomaly, not related to a cultural artefact, is detected in approximately $0.2 \%$ of amniotic fluid cultures, and in about one third of the cases it consists of an autosomal trisomy. ${ }^{1}$ The phenotypic consequences of this anomaly are highly variable, and may depend on several variables, including the specific chromosome involved, the distribution and proportion of the trisomic line in embryonic and extraembryonic lineages, and the presence of uniparental disomy (UPD) in the euploid cell line. Therefore, the finding of a mosaic autosomal trisomy in amniocytes may require additional cytogenetic and/or molecular work and may leave questions unanswered at the time of post-amniocentesis counselling. Such problems are especially compelling when a rare type of mosaicism is diagnosed.

Trisomy 17 is among the rarest mosaic trisomies observed in amniocytes, ${ }^{2}$ with only 12 cases reported so far. $^{2-8}$ No phenotypic abnormalities have been observed in the newborns or foetuses, and whenever additional cell types, mainly peripheral lymphocytes, were examined cytogenetically, these were shown to contain only euploid cells. On the other hand, nothing is known about the possible effects of UPD17 on embryo development, since this condition has never been described before. At the same time, postnatal ascertainment of mosaic trisomy 17 in two children with multiple congenital anomalies/mental retardation ${ }^{9,10}$ indicates that this condition may have harmful effects on development.

We have recently observed three new cases of mosaic trisomy 17 in amniocytes. In each case, different situations were observed after performing additional cytogenetic investigations and a search for UPD with chromosome 17 microsatellite markers. The results of karyotype/genotype analysis were then compared with phenotypic characteristics, which were normal in two and abnormal in one of the cases.

\section{Clinical Reports}

\section{Case 1}

A P4G5 38-year-old woman requested an amniocentesis because of advanced maternal age. A cordocentesis was performed in addition to the amniocentesis. The pregnancy proceeded to term, with the birth of a phenotypically normal girl who weighed $3740 \mathrm{~g}$. When we last saw the child at the age of two years and a half, growth and development were normal.

\section{Case 2}

A P2G3 41-year-old woman requested an amniocentesis in consideration of advanced maternal age. Following the initial results, a repeat amniocentesis and, subsequently, a cordocentesis, were performed. The pregnancy ended spontaneously at week 38 with the birth of a $3030 \mathrm{~g}$ normal boy, whose growth and psychomotor development have been normal so far (age 2 years).

\section{Case 3}

This was the first pregnancy of a 24-year-old mother. Amniocentesis was performed for parental reassurance in the absence of specific risk factors for chromosome or other genetic abnormalities. Following the finding of mosaic aneuploidy, the couple decided to terminate the pregnancy at week 21 . Autopsy findings were as follows: all weight and length measurements were in the range of $-1 \mathrm{SD}$ relative to the reported occurrence of last menses; micrognathia, a large mouth with down-turned corners, and long philtrum were noted; there were no major internal malformations. It should be noted that, in the absence of major phenotypic anomalies, such findings do not necessarily indicate abnormal foetal development.

\section{Materials and Methods}

\section{Chromosome Analysis}

Amniotic fluid cultures were established either by the flask (case 1) or by the in situ (cases 2 and 3) method. Cytogenetic analyses were performed on $\mathrm{G}(\mathrm{GTG})$-banded metaphases.

\section{Analysis of Microsatellite Markers}

PCR amplicification and typing of chromosome 17 microsatellite polymorphisms were performed in the presence of $\alpha-{ }^{32} \mathrm{P}-\mathrm{dCTP}$ followed by electrophoresis onto denaturing polyacrylamide gels. The relative positions of the microsatellite loci investigated were obtained from the Généthon and CHLC maps.

\section{Results}

\section{Case 1}

Following amniocentesis, trisomy 17 was detected in two independent flasks, with a frequency of $22.8 \%$ and $14.2 \%$, respectively (Table 1 ). A subsequent cordocentesis demonstrated a normal female karyotype in all cells examined. Cytogenetic investigation was performed on different tissue samples obtained at the 
Table 1 Summary of cytogenetic, molecular and clinical findings in mosaic trisomy 17 diagnosed at amniocentesis

\begin{tabular}{|c|c|c|c|c|c|c|c|c|c|c|c|}
\hline \multirow[t]{2}{*}{ Case } & \multicolumn{9}{|c|}{ Cytogenetic findings ${ }^{\mathrm{a}}$} & \multirow{2}{*}{$\begin{array}{l}\text { Molecular } \\
\text { findings }\end{array}$} & \multirow[t]{2}{*}{ Phenotype } \\
\hline & $\begin{array}{l}\text { Prenatal } \\
\text { Amniotic fluid } \\
\text { (amniocentesis) }\end{array}$ & $\begin{array}{l}\text { Umbilical } \\
\text { cord blood }\end{array}$ & $\begin{array}{l}\text { Amniotic fluid } \\
\text { (at term) }\end{array}$ & Placenta & Amnion & $\begin{array}{l}\text { Postnatal } \\
\text { Umbilical } \\
\text { cord }\end{array}$ & Skin & Fascia lata & Lymphocytes & & \\
\hline 1 & $\begin{array}{l}\text { Flask 1: } \\
\text { 47,XX,+17[8]/ } \\
\text { 46,XX [27] } \\
\text { Flask 2: } \\
\text { 47,XX,+17[5]/ } \\
\text { 46,XX [30] }\end{array}$ & $\begin{array}{l}46, \mathrm{XX} \\
{[100]}\end{array}$ & $\begin{array}{l}47, \mathrm{XX},+17[1] / \\
46, \mathrm{XX}[129]\end{array}$ & $\begin{array}{l}47, \mathrm{XX},+17[1] / \\
46, \mathrm{XX}[99]\end{array}$ & $\begin{array}{l}47, \mathrm{XX},+17[1] / \\
46, \mathrm{XX}[99]\end{array}$ & $\begin{array}{l}46, \mathrm{XX} \\
{[100]}\end{array}$ & N.I. & N.I. & $\begin{array}{l}46, X X \\
{[200]}\end{array}$ & N.I. & $\begin{array}{l}\text { Normal girl } \\
\text { (2⿺辶/2 years) }\end{array}$ \\
\hline 2 & $\begin{array}{l}\text { 1st culture } \\
47, \mathrm{XY},+17[2 \\
\text { clones }] / \\
46, \mathrm{XY}[6 \text { clones }] \\
\text { 2nd culture } \\
47, \mathrm{XY},+17[4 \\
\text { clones }] \\
46, \mathrm{XY}[9 \text { clones }]\end{array}$ & $\begin{array}{l}46, X Y \\
{[100]}\end{array}$ & N.I. & N.I. & N.I. & N.I. & N.I. & N.I. & $\begin{array}{l}46, X Y \\
{[200]}\end{array}$ & $\begin{array}{l}\text { Maternal } \\
\text { UPD 17; } \\
\text { meiosis II } \\
\text { error }\end{array}$ & $\begin{array}{l}\text { Normal boy } \\
\text { (2 years) }\end{array}$ \\
\hline 3 & $\begin{array}{l}47, \mathrm{XX},+17[4] / \\
46, \mathrm{XX}[46]\end{array}$ & N.I. & N.I. & N.I. & N.I. & N.I. & $\begin{array}{l}47, \mathrm{XX},+17[5] / \\
46, \mathrm{XX}[95]\end{array}$ & $46, \mathrm{XX}[100]$ & N.I. & $\begin{array}{l}\text { Biparental } \\
\text { derivation } \\
\text { of chrom. } \\
17\end{array}$ & $\begin{array}{l}\text { Minor } \\
\text { developmental } \\
\text { anomalies at } \\
\text { foetal autopsy }\end{array}$ \\
\hline
\end{tabular}

${ }^{a}$ Numbers within square brackets indicate the number of metaphases (or clones for the in situ technique) observed with a specific karyotype; N.I.: not investigated. 
moment of delivery. No aneuploid cells were observed in peripheral blood and umbilical cord. Placenta, amniotic fluid, and amnion contained 47,XX, +17 cells at a frequency of $0.8-1 \%$ each (Table 1 ). Molecular investigations for UPD could not be performed due to lack of parental collaboration.

\section{Case 2}

Using the in situ technique, mosaic trisomy 17 was observed in two repeat amniocenteses (Table 1), performed at weeks 17 and 19, respectively. As in case 1, examination of foetal blood lymphocytes was proposed and accepted by the parents. All metaphases scored had a normal male karyotype, which was confirmed after birth on the lymphocytes of the newborn (Table 1).

The parental origin of the chromosome 17 homologues in the newborn was investigated by analysing the segregation of chromosome 17 microsatellite polymorphisms in leukocyte DNA obtained from the child and his parents. A total of 11 markers was found to be informative for the determination of the parental origin of chromosomes 17 and of the non-disjunction stage (Figure 1, Table 2). In detail, six markers (D17S796, D17S122, D17S250, D17S1185, D17S519, and D17S107) proved the maternal derivation of both chromosome 17 homologues in the child, and results obtained on the other five markers were compatible

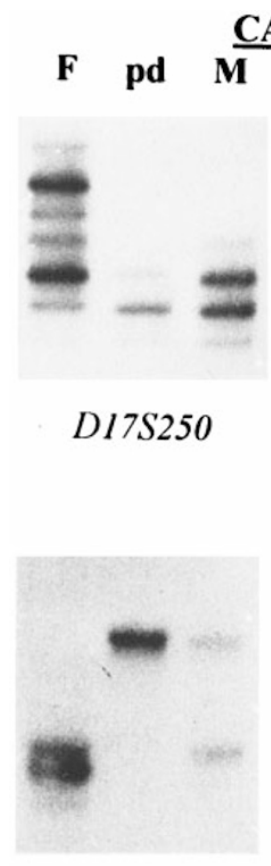

$D 17 S 1185$
CASE 2
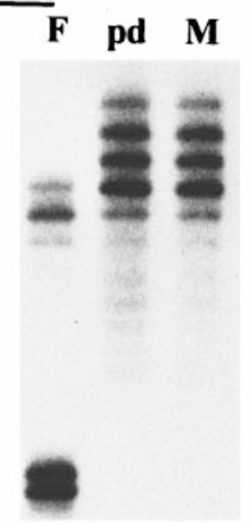

D17S796

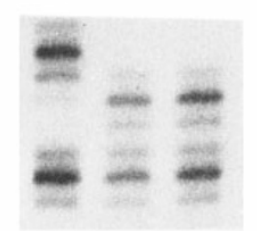

D17S928

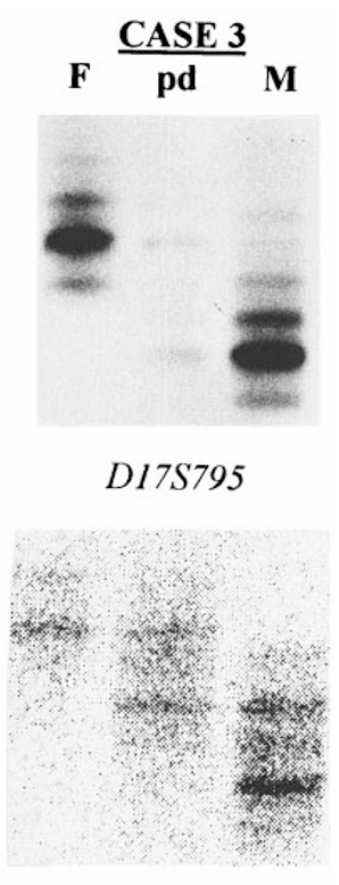

$D 17 S 250$

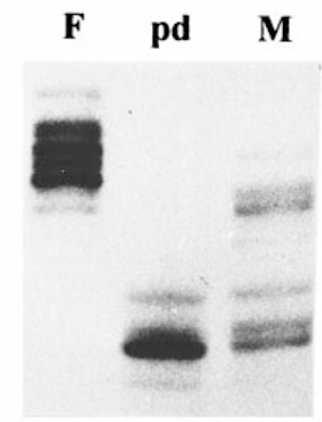

D17S519

Figure 1 Representative results of chromosome 17 microsatellite segregation in Cases 2 and 3. The locus investigated is indicated below each autoradiogram $\mathrm{F}=$ father; $\mathrm{pd}=$ prenatally diagnosed case; $\mathrm{M}=$ mother . 
with this interpretation. The child's chromosome 17 homologues display a condition of proximal (pericentromeric) homozygosity with distal (peritelomeric) heterozygosity, which is indicative of a maternal meiosis II error (Table 2). It is thus likely that the pregnancy started with a trisomic zygote, whose rescue through chromosome loss gave rise to UPD and, specifically, to partial maternal isodisomy 17. Non-paternity was excluded by analysis of microsatellites mapped to five different autosomes.

\section{Case 3}

This case was referred after pregnancy termination. Amniocyte cultures from two repeat amniocenteses had been examined at another laboratory, and the only available information was that mosaic trisomy 17 had been detected (percentage of trisomic cells: $4 \%$ ). Long term cultures were established from foetal skin and fascia lata fibroblasts. Mosaicism for trisomy 17 was detected in $5 \%$ of mitoses derived from the skin, but not in the fascia lata (Table 1).

Analysis of chromosome 17-specific markers performed on foetal skin fibroblast and parental leukocyte DNAs revealed the presence of both a maternal and a paternal allele in the foetus at three informative loci (Table 2, Figure 1).

\section{Discussion}

Predicting the developmental consequences of prenatally diagnosed mosaicism for an autosomal trisomy is often a challenge for the medical geneticist, especially when the finding concerns a rarely observed anomaly. In order to provide data which may be useful for the purpose of genetic counselling, we have performed clinical, pathological, cytogenetic and molecular investigations on three cases of true mosaic trisomy 17 detected on amniotic fluid cells. Mosaicism for trisomy 17 is a rare condition, which has been ascertained both pre- and postnatally. The few prenatally diagnosed cases have been observed in amniocytes (12 cases), ${ }^{2-8}$ and, more rarely, in chorionic villus samples. ${ }^{11}$ In all cases, no major foetal or newborn abnormalities were observed. Cytogenetic follow-up studies did not show any involvement of tissues derived from the embryo proper, as assessed by analysis of umbilical or peripheral blood lymphocytes after birth, which was performed in 9/12 cases diagnosed in amniocytes. ${ }^{2-3,8}$

By contrast with the findings obtained on trisomy 17 mosaicism detected at amniocentesis, two patients who were ascertained postnatally presented with major phenotypic anomalies, including severe developmental delay. ${ }^{9,10}$ Mosaicism for trisomy 17 was detected in skin fibroblasts, but not in peripheral lymphocytes. Segregation analysis of chromosome 17 microsatellite markers indicated a post-mitotic origin of the trisomic line in the skin fibroblasts and ruled out UPD in the lymphocyte, euploid line in one case. ${ }^{10}$

The results obtained in the present study, combined with those of previously reported cases, allow us to draw the following conclusions. First, the presence of mosaic trisomy 17 in amniocytes is most frequently associated with normal embryonic development. In fact, no phenotypic abnormalities were recorded in $14 / 15$ cases. Also, the minor phenotypic anomalies

Table 2 Genotypes at chromosome 17 microsatellite loci in mosaic trisomy 17 detected in amniotic fluid

\begin{tabular}{|c|c|c|c|c|c|c|c|c|c|}
\hline \multirow[t]{3}{*}{ Locus } & \multirow{3}{*}{$\begin{array}{l}\text { Cytogenetic } \\
\text { map location }^{\mathrm{a}}\end{array}$} & \multicolumn{8}{|c|}{ Genotypes ${ }^{\mathrm{b}}$} \\
\hline & & \multicolumn{4}{|c|}{ Case 2} & \multicolumn{4}{|c|}{ Case $3^{c}$} \\
\hline & & Father & Mother & Child & Interpretation $^{\mathrm{d}}$ & Father & Mother & Foetus & Interpretation \\
\hline D17S849 & $?^{\mathrm{e}}$ & $2-3$ & $1-3$ & $1-3$ & Mat. HD & NI & NI & NI & \\
\hline D17S796 & $?$ & $3-4$ & $1-2$ & $1-2$ & Mat. HD & $3-3$ & $1-2$ & $2-3$ & Biparental inheritance \\
\hline$D 17 S 122$ & $17 \mathrm{p} 11.2$ & $1-3$ & $2-2$ & $2-2$ & Mat. HD or ID & NI & NI & NI & \\
\hline$D 17 S 947$ & $?$ & $1-2$ & $1-2$ & $1-1$ & Mat. ID & NI & NI & NI & \\
\hline$D 17 S 250$ & $17 q 11.2-q 12$ & $1-2$ & $2-3$ & $3-3$ & Mat. ID & $1-1$ & $2-3$ & $1-2$ & Biparental inheritance \\
\hline D17S1185 & $17 \mathrm{q} 12-\mathrm{q} 21$ & $2-3$ & $1-2$ & $1-1$ & Mat. ID & NI & NI & NI & \\
\hline D17S519 & ? & $1-2$ & $3-4$ & $4-4$ & Mat. ID & NI & NI & NI & \\
\hline D17S846 & $17 q 21$ & $1-3$ & $2-3$ & $3-3$ & Mat. ID & NI & NI & NI & \\
\hline D17S107 & $17 q 12-q 24$ & $3-3$ & $1-2$ & $1-1$ & Mat. ID & NI & NI & $\mathrm{NI}$ & \\
\hline D17S795 & ? & $1-3$ & $1-2$ & $1-2$ & Mat. HD & $1-1$ & $2-2$ & $1-2$ & Biparental inheritance \\
\hline D17S928 & $?^{\mathrm{f}}$ & $1-3$ & $2-3$ & $2-3$ & Mat. HD & NI & NI & NI & \\
\hline
\end{tabular}

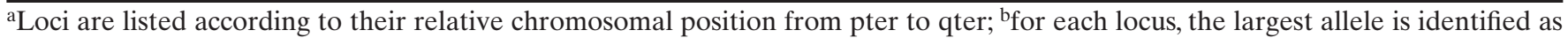
number 1, with other alleles ordered by decreasing size; ${ }^{\mathrm{c}} \mathrm{NI}$ : not investigated; ${ }^{\mathrm{d}}$ Mat. HD: maternal heterodisomy, ID: maternal isodisomy; ${ }^{e}$ this is the most distal locus on $17 \mathrm{p}$ according to the Cooperative Human Linkage Center (CHLC) map (http://www.chlc.org); fthis locus lies in the most distal interval of $17 \mathrm{q}$ according to the CHLC map. 
observed in Case 3 do not imply abnormal development, since autopsy in aborted foetuses is not completely reliable. The fourteen cases with normal outcome did not show any evidence of trisomy 17 in cells derived from the embryo proper. In two cases $\left(^{3}\right.$, and Case 1 in the present study), the results of post-partum cytogenetic investigations were compatible with confined placental mosaicism (CPM). These findings also indicate that CPM for trisomy 17 does not have any major effects on foetal development, even when the proportion of aneuploid cells is elevated.

Second, trisomy 17 mosaicism may alter embryonic development when foetal tissues are involved, as shown by the two reports of phenotypically abnormal liveborn individuals ascertained postnatally. ${ }^{9,10}$ Minor anomalies were also observed in the only case from the present study (Case 3) in which foetal trisomy 17 was documented, although these observations are not sufficient to draw definite inferences on the possible outcome if pregnancy had been continued. At any rate, the abnormal developmental effects associated with trisomy 17 mosaicism must be related to chromosome imbalance, since no evidence of UPD was found in the two abnormal cases $\left({ }^{10}\right.$, and Case 3 in the present study) which were investigated with chromosome 17 polymorphic markers.

Third, mosaic trisomy 17 can arise due to meiotic non-disjunction, followed by chromosome loss and restoration of the euploid status at least in the embryonic lineage. This sequence of events can lead to UPD, as observed in Case 2 from the present study. The normal phenotype of this child indicates that chromosome 17 is not likely to contain developmentally important genes that are maternally imprinted. Further observations will be needed to ascertain whether paternal UPD17 also exists and which are its phenotypic effects, if any.

Finally, what should be the counselling approach when trisomy 17 mosaicism is detected in amniocytes? Available data indicate that the risk of foetal abnormalities is low (probably $<10 \%$ ), and limited to those cases with involvement of foetal tissues. Risk assessment may not be substantially refined by cytogenetic investigation of cord blood lymphocytes, since trisomy 17 was only detected in skin fibroblasts in the phenotypically abnormal child reported by Shaffer et $a l .{ }^{10}$ However, the finding of mosaic trisomy 17 either on late chorionic villus and/or placental biopsy specimens would indicate that the pregnancy most likely started with an aneuploid conceptus. In addition, careful ultrasonographic studies may find evidence of growth retardation and/or other anomalies, which would point towards the presence of aneuploid cells in the foetus, whilst normal growth and morphology would strengthen the assumption of phenotypic normality.

\section{Acknowledgements}

The authors gratefully acknowledge the expert technical assistance of Laura Alesi and Maurizio Graziosi.

\section{References}

1 Hsu LYF, Kaffe S, Jenkins EJ et al: Proposed guidelines for diagnosis of chromosome mosaicism in amniocytes based on data derived from chromosome mosaicism and pseudomosaicism studies. Prenat Diagn 1992; 12: 555-573.

2 Hsu LYF, Yu M-T, Neu RL et al: Rare trisomy mosaicism diagnosed in amniocytes, involving an autosome other than chromosomes $13,18,20$, and 21: karyotype/phenotype correlations. Prenat Diagn 1997; 17: 201-242.

3 Kalousek DK, Dill FJ, Pantzar T, McGillivray BC, Yong SL, Wilson DR: Confined chorionic mosaicism in prenatal diagnosis. Hum Genet 1987; 77: 163-167.

4 Wilson MG, Lin MS, Fujimoto A, Herbert W, Kaplan FM: Chromosome mosaicism in 6000 amniocenteses. Am J Med Genet 1989; 32: 506-513.

5 Welborn JL, Lewis JP: Analysis of mosaic states in amniotic fluid using the in situ colony technique. Clin Genet 1990; 38: 14-20.

6 Djalali M, Barbi G, Grab D: Mosaic trisomy 17 in amniotic fluid cells not confirmed in the newborn. Prenat Diagn 1991; 11: 399-402.

7 Butler MG, Neu RL, Mitchell K: Trisomy 17 detected in amniotic fluid cells but not in newborn infant. Am J Med Genet 1996; 65: 247-248.

8 Djalali M, Barbi G, Mueller-Navia J et al: Further observations of true mosaic trisomy 17 ascertained in amniotic fluid cell cultures. Prenat Diagn 1998; 18: 1191-1194.

9 Bullerdiek J, Bartnitzke S: 46,XY/47,XY, +17 mosaicism in a newborn with multiple malformations. Hum Genet 1992; 60: 296.

10 Shaffer LG, McCaskill C, Hersh JH, Greenberg F, Lupski JR: A clinical and molecular study of mosaicism for trisomy 17. Hum Genet 1996; 97: 69-72.

11 Teshima IE, Kalousek DK, Vekemans MJJ et al: Chromosome mosaicism in CVS and amniocentesis samples. Prenat Diagn 1992; 12: 443-459. 